June 1990

\title{
Alzheimer's Disease and Down's Syndrome: An Overview
}

\author{
Dr.Devanshu Desai, M.B.B.S. \\ Queen's University, Kingston, Ontario
}

Follow this and additional works at: https://jdc.jefferson.edu/jeffjpsychiatry

Part of the Psychiatry Commons

Let us know how access to this document benefits you

\section{Recommended Citation}

Desai, M.B.B.S., Dr.Devanshu (1990) "Alzheimer's Disease and Down's Syndrome: An Overview," Jefferson Journal of Psychiatry. Vol. 8 : Iss. 2 , Article 11.

DOI: https://doi.org/10.29046/JJP.008.2.008

Available at: https://jdc.jefferson.edu/jeffjpsychiatry/vol8/iss2/11

This Article is brought to you for free and open access by the Jefferson Digital Commons. The Jefferson Digital Commons is a service of Thomas Jefferson University's Center for Teaching and Learning (CTL). The Commons is a showcase for Jefferson books and journals, peer-reviewed scholarly publications, unique historical collections from the University archives, and teaching tools. The Jefferson Digital Commons allows researchers and interested readers anywhere in the world to learn about and keep up to date with Jefferson scholarship. This article has been accepted for inclusion in Jefferson Journal of Psychiatry by an authorized administrator of the Jefferson Digital Commons. For more information, please contact: JeffersonDigitalCommons@jefferson.edu. 


\title{
Alzheimer's Disease and Down's Syndrome: An Overview
}

\author{
Dr. Devanshu Desai, M.B.B.S.
}

The association between Alzheimer's Disease and Down's Syndrome is well recognized through clinical observations and genetic studies. However, the exact nature and the implications of this link is far from clear as yet. The challenge of diagnosis, genetics and the differences in clinical presentations of Alzheimer's Disease in relation to the Down's Syndrome are reviewed here. Promising areas of research are pointed out and importance of relevant family history is emphasized. A current knowledge in the subject through various studies is presented.

\section{INTRODUCTION}

The association between Down's Syndrome [DS] and Alzheimer's Disease [AD] has been well recognized for some time now. Senile plaques were first described in DS brains in 1921 by Struwe. In 1948 Jervis described clinical deterioration and Alzheimer's neuropathology in DS. It is also suggested now that this association is two-sided! On one hand individuals with DS tend to develop AD at some point in their lives if they survive long enough (1-5). On the other hand, there have been some reports of higher than expected frequencies of DS in families with AD $(5,6)$. More recently, a gene defect associated with the "familial Alzheimer's Disease" (FAD) has been mapped to chromosome 21, a chromosome related to DS $(7,8)$. Although some of these findings are disputed, it is worthwhile to review current knowledge in the relationship between these two conditions, while awaiting further information about clinicopathological and genetic association between them.

This overview describes each of these two conditions briefly in relation to the other and then examines the association and the implications of this association between them.

In this overview, the term $\mathrm{AD}$ is used to refer to individuals with a provisional diagnosis of Primary Degenerative Dementia of Alzheimer's type.

Address correspondence to Dr. Desai, 425 Mill Road No. 9, Etobicoke, Ontario, Canada, M9C 1 Z2 


\section{Alzheimer's Disease-Diagnostic Accuracy}

Primary Degenerative Dementia-Alzheimer's type, is a neuropathological diagnosis. It is the commonest cause of dementia in the general population and is frequently encountered entity in clinical settings in individuals presenting with symptoms of dementia. AD remains mainly a diagnosis of exclusion. Antemortem diagnostic accuracy depends on variety of factors, including patient selection, diagnostic criteria and assessment methods. The postmortem histological verification of the diagnosis is therefore the gold standard (9).

$\mathrm{AD}$ in persons with a normal karyotype usually begins with learning and memory deficits, and slowly progresses to involve all the aspects of intellectual activity including judgement, calculation and language (10). In the early stages, psychometric assessment indicates more profound impairment of ideomotor performance than language (10). Dalton et al (11) reported that memory loss, depression and disorientation were the most frequently reported early symptoms of $\mathrm{AD}$ in patients with a normal karyotype. In comparison, these are the least frequently reported symptoms in DS individuals who developed AD (11).

There have been several reports systematically describing functional and clinical disturbances in AD in the general population and the reader is advised here to refer to the relevant literature for a detailed description.

The differential diagnosis of dementia has remained a challenge. There are several assessment methods now available which are reasonably sensitive and specific in differentiating causes of dementia. Many investigators have used behavioral observations (12), while the others have used sophisticated neurodiagnostic tools including Computed Tomography (CT), Positron Emission Tomography (PET), Single Photon Emission Computed Tomography (SPECT), Xenon inhalation, Electroencephalography (EEG), Evoked potentials and combinations of these for the etiologic diagnosis of dementia (9). However because of factors such as cost/benefit ratio, sensitivity, specificity and accessibility, these methods have remained research tools at large. At present, there is no 'gold standard' criterion or test for the determination of etiology of dementia in clinical settings. The etiologic diagnosis of dementia is critical because some of the other causes are treatable or at least controllable to some extent.

As mentioned earlier, diagnostic accuracy of AD depends on a variety of factors. Tiemay et al (13) reported that accuracy varied between $81 \%$ and $88 \%$ in clinical settings. A retrospective review by Bolier et al (14) and the report of Joachin et al (15) suggest that elaborate clinical investigations may not enhance diagnostic accuracy. In research settings the diagnostic accuracy may exceed $90 \%$ (9). Morris et al (16) reported $100 \%$ accuracy in a selected sample of 31 cases with strict inclusion and exclusion criteria without any reference to neuropsychological test performance. These findings apply to the general population with normal or unknown karyotype, where, in absence of a 'gold standard', the selection of a sample is extremely difficult. The issue of diagnostic 
accuracy is much more difficult, particularly in the early stage of $\mathrm{AD}$, in the individuals with DS.

\section{Genetics of $A D$}

A genetic basis for some cases of AD was first suggested in 1933 (17). There are case reports describing 'familial Alzheimer's disease' [FAD] $(18,19)$, characterized by early onset dementia. Brietner et al in recent studies $(20,21)$ indicated that the majority of these cases are inherited as an autosomal dominant mutation. In a more recent study (22) they reported a striking increase in cumulative incidence of $\mathrm{AD}$-like illness among the first degree relatives of $\mathrm{AD}$ probands. Bird et al (23) noted significant phenotypic heterogeneity in 180 demented individuals from 24 kindreds. They noted clinical and neuropathological differences among families with AD. They raised questions whether there is more than one type of $\mathrm{AD}$, even among FAD patients and whether the phenotypic heterogeneity represents a genetic heterogeneity or is merely an epiphenomenon. St. George Hyslop et al (8) recently reported FAD linked to two chromosome 21q21 loci in four families. One of these two markers is linked to the amyloid $\mathrm{B}$ gene. Thus the $\mathrm{q} 21$ region of the long arm of chromosome 21 seems to be of particular relevance to AD. Some groups of pedigrees have been assembled in which autopsy determined $\mathrm{AD}$ appears to be inherited as an autosomal dominant trait (24). However, the findings of genetic linkage were disputed by Schellenberg et al (24). They found no evidence of linkage between FAD and chromosome 21 markers, including the amyloid B gene. They obtained strong evidence for genetic heterogeneity when they compared their study group to St. George Hyslop et al's group. In this study, most of the evidence for exclusion of genetic linkage came from presenile onset families, although the age of onset was higher than that in St. George Hyslop et al's group. They mentioned the possibility that the gene in chromosome 21 may account only for very early onset FAD.

There also are some other results suggesting genetic involvement in AD. From Heston et al's careful genetic study (3) of 125 families, some relatives of younger probands from autopsy proven $\mathrm{AD}$ appear to be at increased risk of Down's syndrome, of myeloproliferative disorders and immune system disorders. Kallmann's (25) investigation of twin pairs suggested monozygotic concordance in AD. All these evidences suggest a genetic component in at least some cases of AD. The exact nature of such genetic contribution is yet to be known.

\section{Down's Syndrome}

Ever since the classical description of 'Mongolism' by Langdon Down in 1866, this has remained the most discussed and the most investigated syndrome in the field of mental retardation. The presence of an extra small chromosome was reported by Lejeune in 1959, and was later identified as chromosome 21. 
These patients present with a variety of physical characteristics and clinical problems.

Only two decades ago, very few DS individuals survived through midadulthood because of associated congenital heart disease, recurrent infections and a variety of other problems. With advancing health care and medical technology, more and more of these individuals survive until 40 years and beyond. According to recent data by Baird and Sadovnick (33), 80\% of DS patients without congenital heart disease survive past the age of 30 years. More than $50 \%$ of their DS patients reached their 50's and $13.5 \%$ reached age 68 . These observations are significant in relation to the development of AD neuropathology in these individuals.

Studies have shown a higher than average incidence of hypothyroidism (34-37), and at least average incidence, if not higher, of depression (38) in DS. Hypothyroidism in DS is expressed usually as abnormality in one or more thyroid function tests whereas clinically, most of these individuals are asymptomatic. Hollingworth et al (39) compared T4, T3 and TSH levels in 60 DS patients to controls and did not find a significant difference. However, six DS patients had goiter and seven had exophthalmos without goiter. Mani (40) studied 55 adult hospital DS patients; almost all of them were 40 years or over. He found a high frequency of clinical features suggesting hypothyroidism. He recommended screening thyroid function in all DS individuals over 40 .

In spite of the lack of evidence pointing to specific causes of hypothyroidism, some have suggested autoimmunity as an etiologic factor for underactivity of the thyroid gland (40). Most of these studies found antibodies to thyroid tissue in DS patients. Increased rates of lymphocytic leukemia and other malignancies and a higher incidence of viral and bacterial infections have also been reported (41-43). A higher incidence of congenital hypothyroidism had also been reported (44).

In 1981, Harrell et al (45) reported beneficial effects of vitamins, minerals and thyroid compound in improving intellectual functioning in persons with DS. They did not evaluate thyroid function prior to therapy. Subsequent attempts to replicate these results with vitamin and mineral therapy were unsuccessful (46). Tiurosh and Toub et al (47), in a double blind cross-over drug-placebo trial, studied a small sample to assess the efficacy of short term thyroid supplement in DS individuals with low borderline thyroid function. They found no significant gains with thyroid supplement. Replication of similar results on a larger sample with more attention towards symptoms of dementia is needed to clarify the indications for thyroid supplement in DS individuals.

A high prevalence of psychiatric disorders in the mentally retarded, including those with DS, has been reported (48). Several case reports of major depression in DS patients have been published $(49,50)$, although there have been some unusual presentations and disagreements in the diagnosis of affective disorders in moderate to severe retardation. Estimates of the prevalence of depression in DS are not available at present. Considering mentally retarded of 
all the different etiologies as a single group, it seems likely that affective disorders are at least as common in these individuals as in general population (38). This is particularly significant in DS patient over age of 40 , since it complicates the detection of early AD.

\section{Alzheimer's Disease in Down's Syndrome}

Alongside the clinical observations and genetic studies in AD patients, there are several reports on DS individuals that suggest a striking association between these two conditions. However, the nature and the clinical and genetic implications of this association remains elusive. Neuropathological changes of AD in brains of DS individuals have been reported for more than 50 years now. Since Struwe's report in 1929, it is well recognized from several studies that virtually all DS individuals 37 years or over develop AD neuropathology, namely, extensive neurofibrillatory degeneration and senile plaques, throughout widespread regions of neocortex $(26,27)$; Certain dermatoglyphic patterns are common in DS patients $(28,29,30)$, and the extension of these studies to their parents showed unusual combinations of dermatoglyphic patterns in parents, particularly in a parent in whom non-disjunction occurred (31). Dermatoglyphic changes similar to DS were also observed in AD by Weinrab who reported a high frequency of ulnar loops on fingertips of both AD and DS patients (32). These and other evidences are becoming clearer as the survival of DS individuals is prolonged.

Clinically, some investigators have observed differences in symptoms of AD in DS patients and in general population. Dalton et al (11) reviewed 35 DS cases from several case reports. They examined 18 descriptive terms of functional and clinical features in these cases excluding language based disturbances. They found that the most frequently reported clinico-functional expression in these cases was clinical seizures $(87.8 \%)$; followed by personality changes $(45.5 \%)$ and focal neurological signs (45.5\%). The most frequently reported symptoms in patients with $\mathrm{AD}$ in general population-i.e. memory loss, depression and disorientation-were the least frequently reported in persons with AD in DS. Besides, differences were noted in self help skills and level of activity in these two groups with AD. Although such comparison between unmatched groups and variable interpretations of retrospective clinical records can provide some direction for further research, it serves little in clarifying the confusion regarding the natural history of $\mathrm{AD}$ in $\mathrm{DS}$.

Only one prospective study on AD in DS is reported in literature (51). In this study of 49 clinically demented DS individuals over age 35 followed longitudinally, the average age of dementia onset was $54.2+6.1$ years, which is much earlier than $\mathrm{AD}$ in the general population. In 23 patients who died, the average duration was $4.6+3.2$ years with no significant difference between the sexes. This study was also able to delineate several features of AD in their DS patients. (i) The first signs of dementia in DS-changes in personality such as 
irritability and emotional lability in most cases in their study populationcorrelate with the late features of $\mathrm{AD}$ in general population. (ii) There is a latent period of 2 to 3 decades between the time of onset of neuropathological changes and clinical symptoms. (iii) Prevalence of dementia increases with age. (iv) There is higher incidence of seizures in these individuals as compared to AD patients in general population. (v) Twenty percent of DS outpatients with dementia also developed Parkinson's disease.

\section{DISCUSSION}

The available information about the association between $\mathrm{AD}$ and $\mathrm{DS}$ raises many questions and hypotheses, most of which still remain unanswered. The differences noted in clinical features of AD in DS and in persons with normal karyotype poses a question if there is a different etiology and pathogenesis of $\mathrm{AD}$ in these two groups (11). This questions the significance of pathological changes and the clinicopathological correlation in AD. The issue is further complicated by findings of changes identical to $\mathrm{AD}$ in many elderly brains in absence of clinical symptoms. Interestingly enough, there are at least two case reports of DS patients - one 49 years and the other 47 years of age-who showed no neuropathology of $\mathrm{AD}$ in brain on autopsy $(52,53)$. The prevalence of $\mathrm{AD}$ increases with age in DS as well as general population and it is assumed that the aging process begins early and progresses rapidly in DS individuals (54). These observations support Gowers' concept with the implication that AD represents merely a precocious aging of central nervous system (55). If so, one can assume that every individual who lives long enough will develop $\mathrm{AD}$ at some point. It may be possible that the symptoms appear only when brain changes are extensive enough or when they involve certain brain areas, such as hippocampus.

However, from epidemiological evidence and clinical observations, there is little doubt that a disease process is involved in AD. Besides the issue of causal factors it also remains to be seen if there are separate factors that control the age of onset in $\mathrm{AD}$.

Almost all DS individuals show AD neuropathology at some point, and up to $85 \%$ of these-presumably all if they lived long enough-develop AD (51). Theoretically it seems possible to detect AD in its early phase and to delineate its natural history in this cohort. In that case, the idea of detecting a "herald sign" that predicts or signals the onset of clinical AD appears promising. An individual sign which increases in prevalence with advancing age may need careful scrutiny. Examples of such signs would include primitive reflexes, face-hand test etc., of course, this would require several detailed longitudinal observations.

As mentioned earlier, there are strong indications of a genetic link between $\mathrm{AD}$ and DS. Although a chromosomal abnormality in AD needs further confirmation, if present, it could be of tremendous help in screening potential parents with high risk pregnancies. For clinicians, it would be important to include specific questions in obtaining the family history of individuals with these 
conditions. In conclusion, there is no doubt about the relationship between AD and DS, but there are several unanswered questions regarding the nature of this relationship. The issues of origin, pathogenesis and the natural history of dementia in DS awaits further prospective studies. The group of DS individuals seems a readily available "ideal" cohort because of their almost certainly known outcome. Obviously, this will be a promising area of research in the field of psychiatry and the study of mental retardation.

\section{ACKNOWLEDGEMENT}

Encouragement, guidance and useful suggestions from Dr. Bruce McCreary are gratefully appreciated. Many thanks for his help.

\section{REFERENCES}

1. Heston LL: Down's syndrome and Alzheimer's disease: Defining an association. Psych Develop 12(2):287-294, 1984

2. Ball MJ and Nuttall K: Neurofibrillatory tangles, granulovacuolar degeneration and neuron loss in Down's syndrome: Quantitative comparison with Alzheimer's dementia. Ann Neurol 7:462-465, 1980

3. Heston LL, Mastri AR, Anderson E and White J: Dementia of Alzheimer's type: Clinical, genetics, natural history and associated conditions. Arch Gen Psych 38:10851090

4. Oliver C and Holland AJ: Down's syndrome and Alzheimer's disease: A Review. Psychological Med 16:307-322

5. Heston LL: Alzheimer's disease, trisomy 21 and myeloproliferative disorders: Association suggesting clinical diathesis. Science 196:322-323, 1977

6. Heyman A, Wilkinson WE, Hurwitz BJ, et al: Alzheimer's disease: Genetic aspects and associated clinical disorders. Ann Neurol 14:507-515, 1983

7. Van Broeckhoven C, et al: Failure of familial Alzheimer's disease to segregate with A4-amyloid gene in several European families. Nature 329(6135):153-56, 1987

8. St. George-Hyslop PH, et al: The genetic defect causing familial Alzheimer's disease maps on chromosome 21 . Science 233:885-890, 1987

9. Berg L and Moris JC: Clinical aspects of Alzheimer's disease: Current opinion in Neurol and Neurosurg 2:445-450, 1989

10. Crapper-McLachlan DR, Dalton AJ, Galin H, et al: Alzheimer's disease: Clinical course and cognitive disturbances. Acta Neurol Scand 69/suppl. 99:83-90, 1984

11. Dalton AJ and Crapper-McLachlan DR: Clinical expression of Alzheimer's disease in Down syndrome. Psych Clin North Am 9(4):Dec. 1986

12. Teri L and Larson EB: Behavioral disturbances in dementia of Alzheimer's type. J Am Geriatric Soc 36:1-8, 1988

13. Tierney MC, Fisher RH, Lewis AJ, et al: The NINCDS-ADRDA work group criteria for clinical diagnosis of probable Alzheimer's disease: A clinicopathological study of 57 cases. Neurology 38:359-364, 1988

14. Bolier F, Lopaz OL, Moossy J: Diagnosis of dementia: Clinico-pathological correlations. Neurology 39:76-79, 1989 
15. Joachin CL, Morris JH and Selkoe DJ: Clinically diagnosed Alzheimer's disease: Autopsy results in 150 cases. Ann Neurol 24:50-56, 1988

16. Morris JC, et al: Validation of clinical diagnostic criteria for Alzheimer's disease. Ann Neurol 24:17-22, 1988

17. Gillespie RD: Proc Royal Soc Med 26:1080-1084, 1933

18. Goudsmit J, et al: Familial Alzheimer's disease in two kindreds of the same geographic and ethnic origin: A clinical and genetic study. J Neurol Sci 49:79-89, 1981

19. Nee LE, et al: A family with histologically confirmed Alzheimer's disease. Arch Neurol 40:203-208, 1983

20. Brietner JCS, et al: Familial aggregation in Alzheimer's dementia-I. A model for age dependent expression of an autosomal dominant gene. J Psych Res 20:31-43, 1986

21. Breitner JCS, et al: Familial aggregation in Alzheimer's dementia-II. Clinical, genetic implications of age dependent onset. J Psych Res 20:45-55, 1986

22. Breitner JCS, Silverman JM, Moris RC, et al: Familial aggregation in Alzheimer's disease: Comparison of risk among relatives of early onset and late onset cases and among male and female relatives in successive generations. Neurology 38:207-212, 1988

23. Bird TD, Sumi SM, Nemens EJ, et al: Phenotypic heterogeneity in familial Alzheimer's disease: A study of 24 kindreds. Ann Neurol 25:112-125, 1989

24. Schelienberg GD, et al: Absence of linkage of chromosome 21 q21 markers to familial Alzheimer's disease. Science 241:1507-1510, 1988

25. Kallmann FJ: Heredity in health and mental disorder. W.W. Norton. New York. 1956

26. Wisniewski KE, et al: Occurence of neuropathological changes and dementia of Alzheimer's disease in Down's syndrome. Ann Neurol 17:278-282, 1985

27. Schweber M: Interrelation of Alzheimer's disease and Down's syndrome: In New perspective on Down's syndrome. Baltimore, Md: PH Brooks Publishing Co. 135144,1986

28. Cummins H: Dermatoglyphic stigmata in mongoloid imbeciles. Anat Rec 73:407415,1939

29. Beckman L, et al: Finger and palm dermal ridge patterns in normal and mongoloid individuals. Acta Genet 12:20-27, 1962

30. Holt SB, et al: Fingerprint patterns in mongolism. Ann Human Genet 27:279-282, 1964

31. Ayme S, et al: Dermatoglyphics in parents of children with trisomy 21: Evaluation of their interest in genetic counselling. Clin Genet 15:78-84, 1979

32. Weinreb HJ: Fingerprint patterns in Alzheimer's disease. Arch Neurol 42:50-54, 1985

33. Baird PA and Sadovnick AD: Life expectancy in Down's syndrome. J Pediatrics 110:849-854, 1987

34. Baxter AG, et al: Down syndrome and thyroid function in adults. Lancet ii:794-796, 1975

35. Murdoch JC, et al: Thyroid function in adults with Down's syndrome. J Clin Endocrinol 44:453-458, 1977

36. Korsager S, et al: Thyroid function tests in adults with Down's syndrome. Acta Endocrinologica 88:48-54, 1978 
37. Lobo EH, et al: Community study of hypothyroidism in Down's syndrome. Brit Med J 280:1253, 1980

38. James FE and Snath RP: Psychiatric illness and mental handicap. London, Gaskell Press

39. Hollingworth DR, et al: Goitre, immunological observations and thyroid tests in Down's syndrome. Am J Dis Childhood 127:524-527, 1974

40. Mani C: Hypothyroidism in Down's syndrome. Br J Psych 153:102-104, 1988

41. Muller ME: Neoplasia and Down's syndrome. Ann of NY Acad of Sci 171:639-644, 1970

42. Oster J, et al: Mortality and life table in Down's syndrome. Acta Ped Scand $64: 322-326,1975$

43. Fialkow PJ: Thyroid autoimmunity and Down's syndrome. Ann NY Acad Sci 171:500-511, 1970

44. Fort $\mathrm{P}$, et al: Abnormalities of thyroid function in infants with Down's syndrome. J Ped 104:545-549, 1984

45. Harrell RF, et al: Can nutritional supplements help mentally retarded children? An exploratory study. Proc of National Acad of Sci of USA (Washington) 78:574-578, 1981

46. Bennett FC, et al: Vitamin and mineral supplementation in Down's syndrome. Pediatrics 72:707-713, 1983

47. Tirosh E, Taub Y, et al: Short term efficacy of thyroid hormone supplementation for patients with Down's syndrome and low borderline thyroid function. Am J Mental Retard 83(6):652-656, 1989

48. Minolascino FJ: Psychiatric aspects of Mongolism. Am J Mental Deff 69:653-660, 1965

49. Roith AJ: Psychotic depression in a Mongol. J Mental Subnorm 7:45-47, 1961

50. Keegan DL, et al: Psychosis in Down's syndrome treated with amitriptyline. Can Med Assoc J 110:1128-29, 1974

51. Lal F and Williams RS: A prospective study of Alzheimer's disease in Down's syndrome. Arch Neurol Aug 46:849-853, 1989

52. Whalley LJ: The dementia of Down's syndrome and it's relevance to etiological studies of Alzheimer's disease. Ann of NY Acad of Sci 396:39-53

53. Sylvester PE, et al: Scientific studies in mental retardation. London, The Royal society and McMillan press. 1984

54. Thase ME, et al: Age related neuropsychological deficits in Down's syndrome. Biol Psychiatry 19:571-585, 1984

55. In Lishman WA, Organic Psychiatry: The psychological consequences of cerebral disorder. Second edition. Blackwell Scientific Publication 